Canadian Journal of Fisheries and Aquatic Sciences, 1993, v. 50, n. 4, pp. 781-788. http://pubs.nrc-cnrc.gc.ca/eng/home.html http://pubs.nrc-cnrc.gc.ca/rp-ps/journalDetail.jsp?jcode=cjfas\&lang=eng ISSN: 1205-7533

DOI: $10.1139 / \mathrm{f} 93-090$

(C) National Research Council of Canada. 


\title{
Interactive Influence of Turbidity and Light on Larval Bluegill (Lepomis macrochirus) Foraging
}

\author{
Jeffrey G. Miner ${ }^{1}$ and Roy A. Stein \\ Department of Zoology, and The Ohio Cooperative Fish and Wildife Research Unit, ${ }^{2}$ The Ohio State University, Columbus, OH 43210, USA
}

Miner, J.G., and R.A. Stein. 1993. Interactive influence of turbidity and light on larval bluegill (Lepomis macrochirus) foraging. Can. J. Fish. Aquat. Sci. 50: 781-788.

In a series of in situ enclosure experiments with larval bluegill (Lepomis macrochirus), we demonstrate that turbidity from suspended sediments reduces bluegill consumption of crustacean zooplankton, primarily cyclopoid copepods and copepod nauplii. However, this reduction occurred only when light intensity in parts of enclosures fell below a threshold, estimated at $<450 \mathrm{~lx}$. Following recent studies demonstrating copepod diel vertical migration in response to predators, it appears that copepods in our experiments used low-light strata as a refuge. Without this apparent refuge present, larval bluegill consumption increased with increasing turbidity, but prey were smaller on average. Thus, prey biomass consumed by larval bluegill did not differ with turbidity in high-light conditions. We postulate that the shift to smaller prey across taxa at higher turbidity, when light intensity exceeded $450 \mathrm{~lx}$, derives from increased prey-background contrast. In low-light conditions, larval bluegill consumed larger, but fewer, zooplankton with increasing turbidity, resulting in lower prey biomass consumed. Thus, we demonstrate the field conditions causing negative turbidity effects on larval fish foraging success, and thus growth and recruitment.

\begin{abstract}
Dans une série d'expériences in situ (dans une enceinte) avec des larves de crapet arlequin (Lepomis macrochirus), nous avons démontré que la turbidité provoquée par les sédiments en suspension réduisait la consommation de crustacés zooplanctoniques, surtout des copépodes cyclopides et des nauplii de copépodes. Toutefois, cette réduction ne s'observait que lorsque l'intensité lumineuse dans certaines partie de l'enceinte était inférieure à une valeur seuil estimée à $<450 \mathrm{~lx}$. Des études de suivi récentes ayant montré la migration verticale nycthéméral des copépodes en réponse à l'action des prédateurs, il semble que dans nos expériences les copépodes aient utilisé les couches de faible intensité lumineuse comme refuge. Sans la présence de ce refuge apparent, la consommation des crapets larvaires augmentait avec l'accroissement de la turbidité, mais les proies étaient en moyenne plus petites. Ainsi, la biomasse des proies consommées par les crapets larvaires n'a pas changé avec la turbidité dans des conditions d'intensité lumineuse élevée. Nous avons postulé que le changement vers la consommation de proies plus petites dans l'ensemble des taxons en présence d'une turbidité plus élevée, lorsque I'intensité lumineuse dépasse $450 \mathrm{~lx}$, est attribuable une augmentation du contraste entre les proies et le fond. Dans des conditions de faible luminosité, les crapets larvaires ont consommé du zooplancton moins nombreux, mais plus gros, au fur et à mesure qu'augmentait la turbidité, avec le résultat que la biomasse des proies consommées est plus petite. Ainsi, nous avons démontré les conditions qui, sur le terrain, sont à l'origine des effets négatif́s liés à la turbidité sur l'alimentation des poissons larvaires et, par conséquent, sur la croissance et le recrutement.
\end{abstract}

Received lune 2, 1992

Reçu le 2 juin 1992

Accepted October 26, 1992

( $J B 507)$

Accepté le 26 octobre 1992

S

urvival of larval fish largely depends on size-selective predation (see reviews in Blaxter 1986; Miller et al. 1988).

Therefore, any environmental factors affecting larval growth or exposure to predation should influence recruitment success (Miller et al. 1988; Margulies 1990). Turbidity from suspended sediments is a common feature of many lakes and reservoirs, particularly those in agricultural watersheds, and, along with sedimentation, is a major factor in rivers and lakes that can affect organisms throughout the aquatic community (see reviews in Muncy et al. 1979; Arruda et al. 1983; Wilber 1982; Bruton 1985; Goldsborough and Kemp 1988). Herein,

\footnotetext{
'Present address: Department of Zoology, Miami University, Oxford, OH 45056, USA.

${ }^{2}$ The Unit is sponsored jointly by the United States Fish and Wildife Service, Ohio Department of Natural Resources, The Ohio State University, and the Wildlife Management Institute.
}

we quantify how turbidity from suspended sediments influences foraging success by larval fish, interpreting these results in the context of larval growth, predation risk, and recruitment.

For particulate feeding juvenile and adult fishes, turbidity reduces foraging ability by reducing reaction distance (i.e., maximum distance for detecting prey and predators, Vinyard and O'Brien 1976; Crowl 1989). However, studies with larval fishes have produced conflicting results; turbidity has decreased, increased, and had no effect on foraging success or growth rate (Johnston and Wildish 1982; Boehlert and Morgan 1985; Breitburg 1988; Chesney 1989).

In studies where foraging rate by larval fish declined with increasing turbidity, results were postulated to occur because of reduced reaction distances (Johnston and Wildish 1982; Breitburg 1988), as has been demonstrated for adult fishes (Vinyard and O'Brien 1976; Barrett et al. 1992). Conversely, when turbidity enhanced foraging success of larval fishes, 
increasing contrast between prey and background has been suggested as the mechanism (Boehlert and Morgan 1985). Finally, the lack of a turbidity effect on larval striped bass (Morone saxatilis) growth (Chesney 1989), as turbidity increased from 0 to 130 nephelometric turbidity units (NTU; APHA et al. 1985), a typical range in estuaries and turbid reservoirs, suggests that other interacting variables affect foraging success.

Light intensity reduces foraging rate and growth of larval fish at levels $<100 \mathrm{~lx}$, although the rate of decline and exact light conditions causing the decline vary among species (see review in Blaxter 1986). For striped bass larvae, growth in clear water declines exponentially as light intensity falls from 300 to $0.4 \mathrm{~lx}$, while growth does not change above $450 \mathrm{~lx}$ (Chesney 1989). When turbidity negatively affects foraging (Johnston and Wildish 1982; Breitburg 1988), light intensity above laboratory containers has been $<300 \mathrm{~lx}$ and as low as $5 \mathrm{~lx}$. Positive effects of turbidity on larval fish feeding occurred when light intensity was $>800 \mathrm{~lx}$ (Boehlert and Morgan 1985).

Hence, increased turbidity in lakes and rivers may influence larval fish feeding rates primarily through increased light attenuation, which may result in suboptimal light conditions for foraging. In addition, turbidity can alter prey-background contrast (Hinshaw 1985), as well as affect vertical distribution of fish larvae (Swenson and Matson 1976; Matthews 1984) and zooplankton (Zettler and Carter 1986). Given that light intensity declines with depth, results from experiments in shallow aquaria may not accurately reflect effects of turbidity on larval fish foraging in the field where predator and zooplankton prey can select optimal depths. Therefore, we designed field enclosure experiments using larval bluegill (Lepomis macrochirus), a common limnetic species that feeds on zooplankton (Werner 1967; Werner and Hall 1988; DeVries et al. 1991), to determine how turbidity influences its foraging in situ.

\section{Methods}

Foraging experiments were conducted on each of four consecutive days in Stonelick Lake, a 69-ha reservoir in southwest Ohio with an upstream-to-downstream turbidity gradient reflected by typical Secchi depths of about $20-120 \mathrm{~cm}$, respectively. For these experiments, we placed two transparent polyethylene enclosures (1-m diameter) at each of three sites along the gradient. Depth was $1.7,1.5$, and $1.1 \mathrm{~m}$ at the low-, intermediate-, and high-turbidity sites, respectively; enclosures extended through the entire water column, but were closed at the bottom, excluding the mud substrate. Turbidity was ambient in the two lower turbidity treatments (i.e., about 10 and 20 NTU, Sargent-Welch turbidimeter). To attain the highturbidity treatment of about 30-40 NTU, we added small quantities of bottom sediments (i.e., from $50-\mathrm{cm}$ sediment cores at the high-turbidity site) to enclosures the day before an experiment began. However, during one set of experiments, too much sediment was added to one enclosure resulting in a turbidity of 64 NTU.

Enclosures were filled $1 \mathrm{~d}$ before an experiment with filtered (60- $\mu \mathrm{m}$ mesh) water pumped from a depth of $1 \mathrm{~m}$. To generate similar zooplankton assemblages among turbidities, organisms for all enclosures were collected at the intermediate-turbidity site. Water was pumped from a depth of $1 \mathrm{~m}$ and two times the volume of a single enclosure filtered through a $60-\mu \mathrm{m}-\mathrm{mesh}$ net. After thorough mixing, the zooplankton sample was split equally and half was introduced into each of the two enclosures within a turbidity treatment. Because of travel time between turbidity treatment sites, we did not completely randomize inoculations of zooplankton among enclosures.

Larval bluegill ( $12.5 \pm 0.08 \mathrm{~mm}$ total length, $\dot{X} \pm \mathrm{SE}$ ) were collected from a nearby pond, held in the laboratory for at least $48 \mathrm{~h}$, and fed Artemia sp. nauplii and a mixed culture of zooplankton (mostly copepods) daily. Larvae were then starved for about $18 \mathrm{~h}$ before release into enclosures. We added 15, 13, and 10 bluegill to low-, intermediate-, and high-turbidity enclosures, respectively; this resulted in a consistent density of $1 \|$ larvae $\cdot \mathrm{m}^{-3}$ among enclosures of different depths. Peak density of bluegill larvae in Stonelick Lake averages $2.2 \mathrm{fish} \cdot \mathrm{m}^{-3}$ (DeVries et al. 1991).

Bluegill larvae were introduced into $3-\mathrm{L}$ containers (with $500-\mu m$-mesh sides), which were hung inside enclosures overnight. Before release of larvae into enclosures, water in each enclosure was mixed to resuspend sediments and zooplankton were sampled (i.e., after mixing). Water was not mixed during these short-term experiments because turbidity never declined sufficiently to cause turbidity in any treatments to overlap (i.e., maximum change at lowest and highest turbidity during experiments was about 2 and 10 NTU, respectively). Zooplankton were sampled with a $5.1 \mathrm{-cm}$-diameter tube, collecting $\geqslant 5 \mathrm{~L}$ of water from the entire water column. Water was filtered through a $60-\mu m-m e s h$ net and zooplankton were preserved in $10 \%$ formalin.

Bluegill larvae were released into enclosures at 9:00-10:00 and allowed to feed for 3.5-5.5 h, which ensured evacuation of initially ingested prey. Starved larvae select larger prey at first-feeding than are consumed during continuous feeding (Confer and O'Bryan 1989). We did not determine gut passage time explicitly for bluegill, but larvae of another centrarchid, largemouth bass (Micropterus salmoides), evacuate in about $2 \mathrm{~h}$ at $22-23^{\circ} \mathrm{C}$ (Laurence 1971). Water temperature in our enclosures was $24-27^{\circ} \mathrm{C}$. Because evacuation rate increases with temperature, we believe that initially eaten prey had passed through larval guts within the duration of our experiments.

At experiment's end, turbidity was measured at the $0.5-\mathrm{m}$ depth in all enclosures. In two sets, light intensity (measured as illuminance with a LICOR LI-188b photometer), dissolved oxygen, and temperature were measured at $0.5-\mathrm{m}$ depth intervals in one enclosure for each turbidity treatment. Water was pumped out of enclosures (i.e., duration $=-10 \mathrm{~min}$ ) and bluegill larvae were filtered from this water. Not all larvae were retrieved intact because of pump damage; those collected were preserved in $10 \%$ formalin.

To quantify zooplankton abundance and composition, we identified at least 200 crustacean zooplankters from each sample. These organisms were obtained by adding the entire sample to a graduated cylinder and then removing vertically well-mixed subsamples with a large-bore ( 8 -mm-diameter) pipette. The first 10 individuals identified of each taxon per sample were measured for length (nearest $0.034 \mathrm{~mm}$, excluding spines and caudal rami); these lengths were converted to biomass using length dry weight regressions (Dumont et al. 1975; G.G. Mittelbach, Kellogg Biological Station, Michigan State University, East Lansing, Mich., unpublished data).

We identified prey to the lowest taxon possible $(86 \%$ of cladocerans to genus and $98 \%$ of adult copepods to suborder) in guts of $5-15$ bluegill larvae from each enclosure. Up to 10 prey $\operatorname{tax}^{-1}$. fish ${ }^{1}$ were measured for length to estimate biomass consumed. We used Chesson's alpha (Chesson 1978, 1983), which compares the proportion of each taxon in the diet and in zooplankion samples, to quantify selection of prey by 
TABLE 1. Light intensity (lx) across turbidities in enclosures with foraging bluegill larvac during low and high ambient light in Stonelick Lake, Ohio

\begin{tabular}{crrrrrrrrr}
\hline & \multicolumn{3}{c}{ Low light (set 3) at turbidity (NTU): } & & \multicolumn{4}{c}{ High light (set 4) at turbidity (NTU): } \\
\cline { 2 - 4 } Depth (m) & 11.5 & 18 & 43 & 64 & & 10.5 & 19.5 & 31 \\
\hline 0.0 & 7540 & 8400 & 4080 & 5020 & & 63000 & 57000 & 65400 \\
0.5 & 1960 & 1590 & 210 & 180 & & 21400 & 10000 & 6980 \\
1.0 & 457 & 314 & 14 & 5 & & 5500 & 1200 & 479 \\
\hline
\end{tabular}

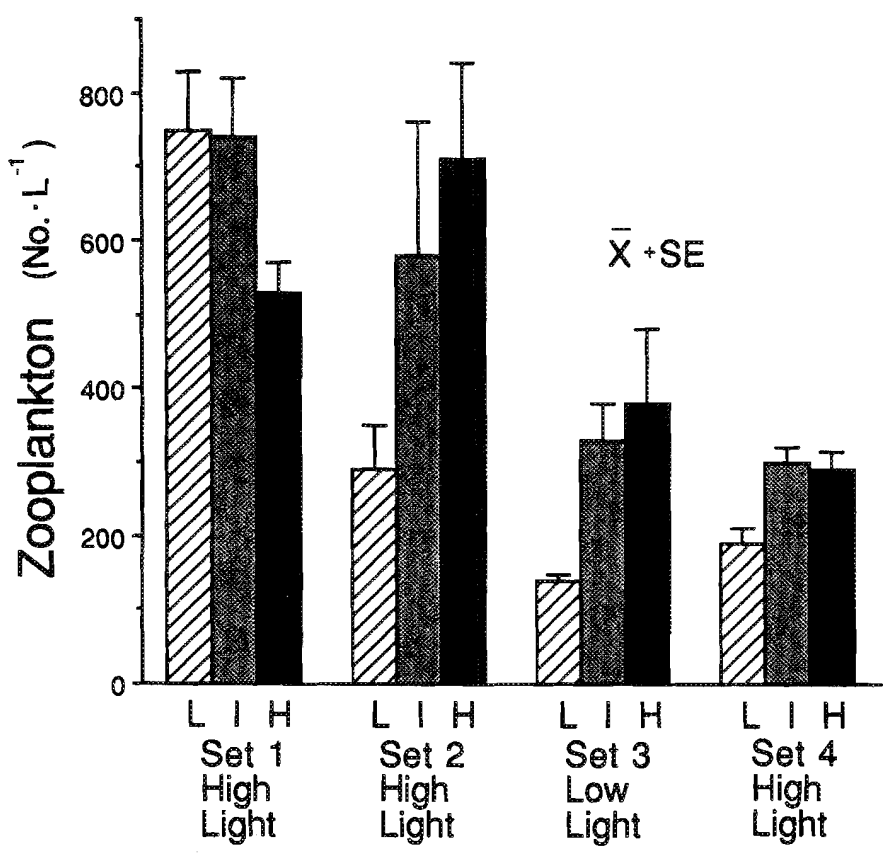

FIG. 1. Zooplankon density in enclosures with varying turbidity in Stonelick Lake, Ohio, on four consecutive days. Enclosures were placed at low (L), intermediate (l), and high $(\mathrm{H})$ turbidity sites within the lake. Standard errors are based on a single sample from each of two enclosures at each site.

larval bluegill. Because enclosures were the experimental units, proportions in the diet for alpha calculation were determined by pooling numbers consumed by all fish within each enclosure, rather than calculating alpha for individual fish and averaging for an enclosure (see Cochran (1977) for a discussion of ayerages of ratios). The formula for this index is

$$
\text { alpha }=\frac{r_{i} / p_{i}}{\sum\left(r_{i} / p_{i}\right)}
$$

where the proportion of prey item $i$ is $p_{i}$ for the environment (enclosures) and $r_{i}$ for the diet. The index ranges from zero to 1 , with zero indicating complete avoidance of the prey taxon.

To determine if initial zooplankton densities in enclosures differed among turbidity treatments (sites) and sets (dates), we conducted two-way ANOVA of total zooplankton density (log transformed). There was significant interaction between treatments and sets $(F=3.3$; df $=6,12 ; p=0.037)$, suggesting patchy zooplankton distribution (Fig. 1). However, the range of zooplankton density was similar among turbidity treatments over the course of the experiment; therefore, we analyzed data for prey consumption as a function of turbidity, using multiple linear regression analysis, including zooplankton density as an independent variable.

\section{Results}

Light intensity was high for sets 1, 2, and 4 because there was little or no cloud cover. Overcast conditions prevailed during set 3 such that surface light intensity was reduced by $90 \%$ relative to set 4 (Table 1 ). Light intensity was not measured in sets 1 and 2, although weather conditions were similar to those in set 4 . At $1-\mathrm{m}$ depth in set 3 . light intensity ranged between 5 and $460 \mathrm{~lx}$ from the highest $(64 \mathrm{NTU})$ to lowest (11 NTU) turbidity (illuminance measured before an enclosure was drained) whereas in high-light conditions, light intensity remained $>460 \mathrm{~lx}$ for all turbidities and depths (Table 1). Because low light $(<100-300 \mathrm{~lx})$ influences larval fish feeding and growth (Blaxter 1986: Chesney 1989), we analyzed high-light and low-light data separately.

\section{Abundance in Diet}

Number of zooplankton consumed by bluegill larvae was correlated with turbidity, but responses differed with light intensity (Fig. 2). At high light. larvae ate more zooplankton as turbidity increased $\left(r^{2}=0.35 ; p=0.006 ; N=18\right)$, while fewer zooplankton were consumed with increasing turbidity at low light $\left(r^{2}=0.86 ; p=0.005 ; N=6\right)$. Regardless of light intensity, neither zooplankton density nor the interaction between turbidity and density improved the fit of these models ( $p=0.51$ and 0.79 , respectively, at high light and $p=0.48$ and 0.37 , respectively, at low light from multiple linear regressions). No zooplankton density effect was detectible, even though there was a wide range of density among enclosures (i.e., 125-800 organisms $\cdot \mathrm{L}^{-1}$ ).

Among prey groups, cyclopoid copepods and copepod nauplii were selected by bluegill larvae. while copepod nauplii and the cladocerans Bosmina longirostris and Ceriodaphnia sp. were the most common prey in the environment (Fig. 3). Cyclopoid copepods and copepod nauplii consistently composed about $70 \%$ of prey consumed.

Because high and low light intensities occurred during different sets, differences attributed to light intensity - turbidity interactions may have derived from date effects. However, other variables potentially affecting larval bluegill foraging, such as dissolved oxygen concentration and temperature, were consistent during this 4 -d experiment (Table 2). Hence, we conclude that larval bluegill foraging was influenced by light intensity as mediated through turbidity.

\section{Prey Selection}

To determine if turbidity affected prey selection, we regressed Chesson's alpha for each taxon against turbidity at high and low light. If turbidity failed to modify prey selection by larvae ( $t$-test of slope, $p>0.05$ ), we compared mean selectivity across turbidities to an expected value based on neutral 
TABLE 2. Physical conditions in enclosures during larval bluegill foraging trials in Stonelick Lake, Ohio, June 27-30, 1988. Turbidity, temperature, and dissolved oxygen data were taken at $0.5 \mathrm{~m}$.

\begin{tabular}{lrcrc}
\hline & \multicolumn{5}{c}{ Day } \\
\cline { 2 - 5 } & \multicolumn{1}{c}{1} & 2 & 3 & 4 \\
\hline Turbidity (NTU) & & & & \\
$\quad$ Low & 9,10 & 8,9 & $11,11.5$ & $10,10.5$ \\
$\quad$ Intermediate & $16.5,17$ & $17.5,18$ & $18,19.5$ & $19,19.5$ \\
High & 29,29 & $39,39.5$ & 43,64 & 31,31 \\
Temperature $\left({ }^{\circ} \mathrm{C}\right)$ & $25.5-27$ & 24 & 25 & $24-26$ \\
Oxygen $\left(\mathrm{mg} \cdot \mathrm{L}^{-\cdots}\right)$ & $9.9-11.6$ & - & - & $8.6-9.8$ \\
\hline
\end{tabular}

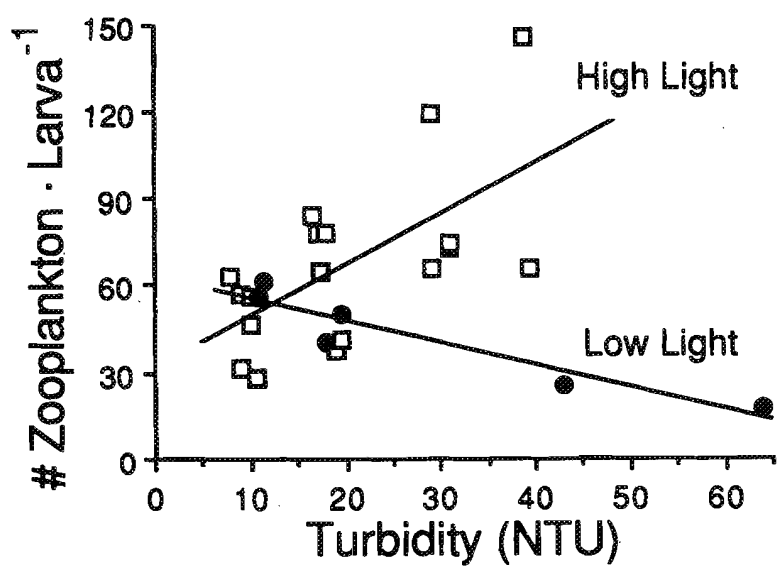

Fig. 2. Mean number of zooplankton consumed per larval bluegill from each enclosure in high-light (cloudless) and low-light (overcast) treatments in Stonelick Lake, Ohio. Each symbol represents a mean per enclosure ( $N=5-15$ per enclosure).

selection (i.e., the reciprocal of the number of prey taxa in the environment, which in this case was alpha $=0.14$ ).

At high light, only selection for copepod nauplii and calanoid copepods changed as a function of turbidity (Table 3 ). Copepod nauplii were negatively selected at low turbidity (alpha $=0.02$ $\pm 0.01 ; \bar{X} \pm \mathrm{SE}$ ). However, selection for copepod nauplii increased with increasing turbidity, resulting in positive selection at the highest turbidity (alpha $=0.33 \pm 0.10$; Fig. 3). In contrast, as turbidity increased, selection for calanoid copepods declined, and was always less than neutral selection (alpha = $0.05 \pm 0.02$ at about $10 \mathrm{NTU}$; Table 3). Although selection for other taxa was unaffected by turbidity at high light, cyclopoid copepods and Diaphanosoma leuchtenbergianum were consistently preferred by larval bluegill (alpha $=0.43 \pm 0.04$ and $0.32 \pm 0.05$, respectively); conversely, $B$. longirostris, Ceriodaphnia sp., and Daphnia parvula were negatively selected (alpha $\leqslant 0.05$; Table 3 ).

Low light occurred during only one set of experiments; thus, sample size $(N=6)$ and the power to detect changes in selection were low. Given this caveat, prey selection did not change across turbidity for any prey at low light intensity $(p>0.05$; Table 3). As in high light, cyclopoid copepods were positively selected at all turbidities (alpha $=0.62 \pm 0.05$; Table 3) whereas small cladocerans (i.e. B. longirostris and Ceriodaphnia sp.), calanoid copepods, and copepod nauplii were negatively selected (Table 3 ).
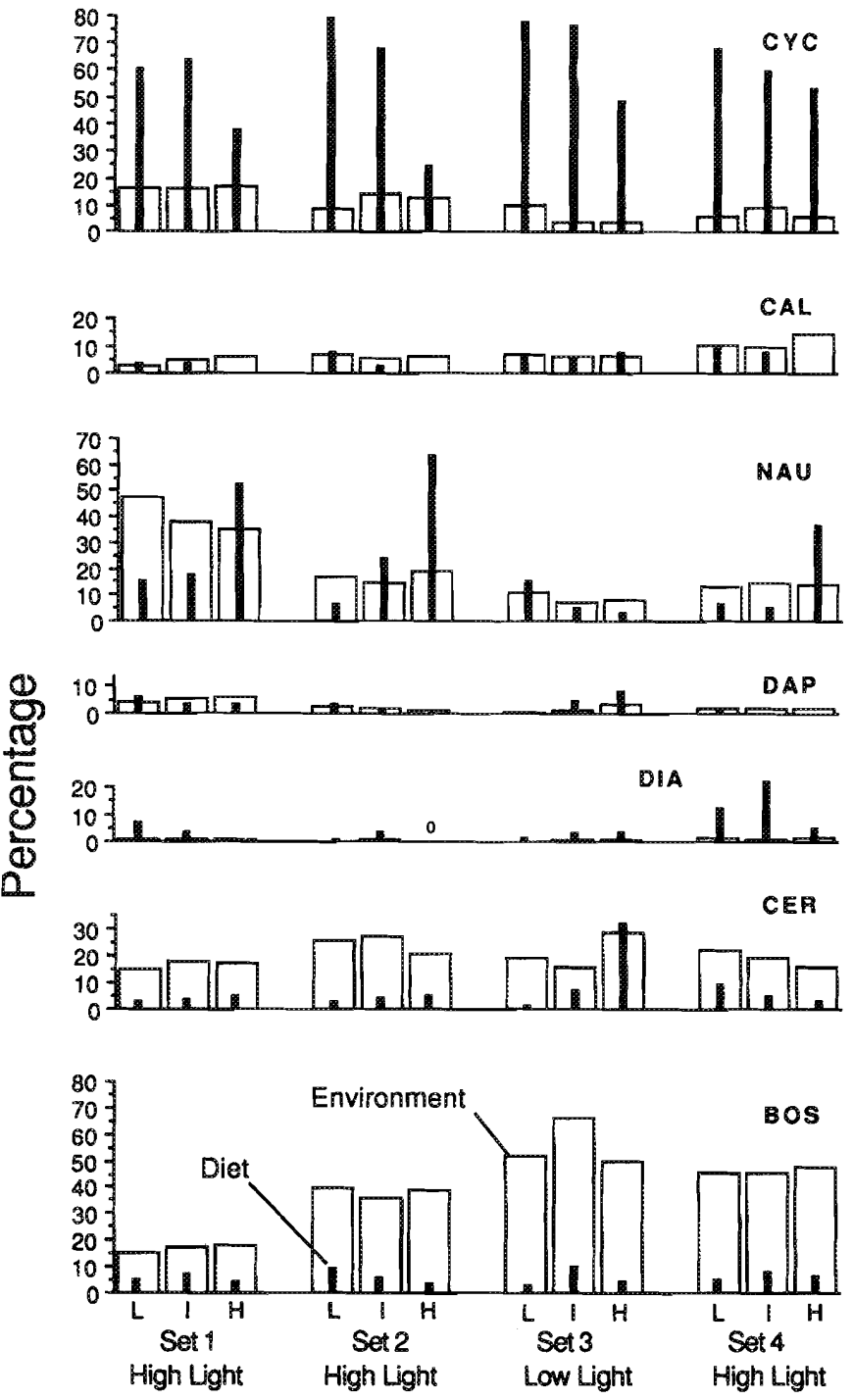

FIG. 3. Proportional abundance of zooplankton in enclosures and in diet of larval bluegill in Stonelick Lake, Ohio, at low (L), intermediate (I), and high $(\mathrm{H})$ turbidity. CYC, cyclopoid copepods; CAL, calanoid copepods; NAU, copepod nauplii; DAP, Daphnia parvula; DIA, Diaphanosoma leuchtenbergianum; CER, Ceriodaphnia sp.; BOS, Bosmina longirosiris.

\section{Size Selection}

Mean length (log transformed) of zooplankters consumed by larval bluegill declined as turbidity increased at high light intensity, corresponding to the increased selection for copepod nau- 
TABLE 3. Regression analysis of prey selection (using Chesson's alpha, Chesson 1978, 1983) by iarval bluegill in enclosures in Stonelick Lake, Ohio, as a function of turbidity at high-light (cloudless) and low-light (overcast) intensity. When slopes did not differ from zero ( $t$-test, $p<0.05)$, mean alphas were compared with neutral selection (i.e., 0.14 , reciprocal of the number of prey taxa in the environment). A dash indicates that the mean was not calculated because turbidity affected prey selection by larvae.

\begin{tabular}{|c|c|c|c|c|c|c|c|c|c|c|c|c|}
\hline \multirow[b]{3}{*}{ Prey taxa } & \multicolumn{6}{|c|}{ High light $(N=18)$} & \multicolumn{6}{|c|}{ Low light $(N=6)$} \\
\hline & \multicolumn{3}{|c|}{$H_{6}:$ slope $=0$} & \multicolumn{3}{|c|}{$H_{0}:$ mean $=0.14$} & \multicolumn{3}{|c|}{$H_{0}:$ slope $=0$} & \multicolumn{3}{|c|}{$H_{0}:$ mean $=0.14$} \\
\hline & $t$ & $p>t$ & $r^{2}$ & alpha $\pm \mathrm{SE}$ & $t$ & $p>t$ & $t$ & $p>t$ & $r^{2}$ & alpha $\pm \mathrm{SE}$ & $t$ & $p>t$ \\
\hline \multicolumn{13}{|l|}{ Copepods } \\
\hline Nauplii & 4.91 & $<0.001$ & 0.60 & - & - & - & -1.79 & 0.15 & 0.45 & $0.04 \pm 0.02$ & -5.37 & $<0.01$ \\
\hline Calanoid & -2.90 & 0.01 & 0.34 & - & - & - & 0.42 & 0.70 & 0.04 & $0.05 \pm 0.01$ & -6.68 & $<0.01$ \\
\hline Cyclopoid & -0.79 & 0.44 & 0.04 & $0.43 \pm 0.04$ & 6.50 & $<0.001$ & -0.31 & 0.77 & 0.02 & $0.62 \pm 0.05$ & 10.40 & $<0.01$ \\
\hline \multicolumn{13}{|l|}{$\begin{array}{l}\text { Cladocerans } \\
\text { Rosmina }\end{array}$} \\
\hline longirostris & -0.42 & 0.68 & 0.01 & $0.01 \pm 0.00$ & -51.13 & $<0.00$ & -0.63 & 0.56 & 0.09 & $0.00 \pm 0.00$ & -156.3 & $<0.001$ \\
\hline Ceriodaphnia sp. & 1.90 & 0.08 & 0.18 & $0.01 \pm 0.00$ & -85.71 & $<0.001$ & 1.80 & 0.15 & 0.45 & $0.02 \pm 0.01$ & -12.43 & $<0.001$ \\
\hline Daphnia parvula & -1.36 & 0.19 & 0.10 & $0.05 \pm 0.01$ & -7.05 & $<0.001$ & -0.75 & 0.49 & 0.12 & $0.10 \pm 0.03$ & -1.31 & $>0.2$ \\
\hline $\begin{array}{l}\text { Diaphanosoma } \\
\text { leuchtenbergianum }\end{array}$ & -1.62 & 0.13 & 0.14 & $0.32 \pm 0.05$ & 3.62 & $<0.01$ & 2.13 & 0.10 & 0.53 & $0.16 \pm 0.03$ & 0.58 & $>0.5$ \\
\hline
\end{tabular}

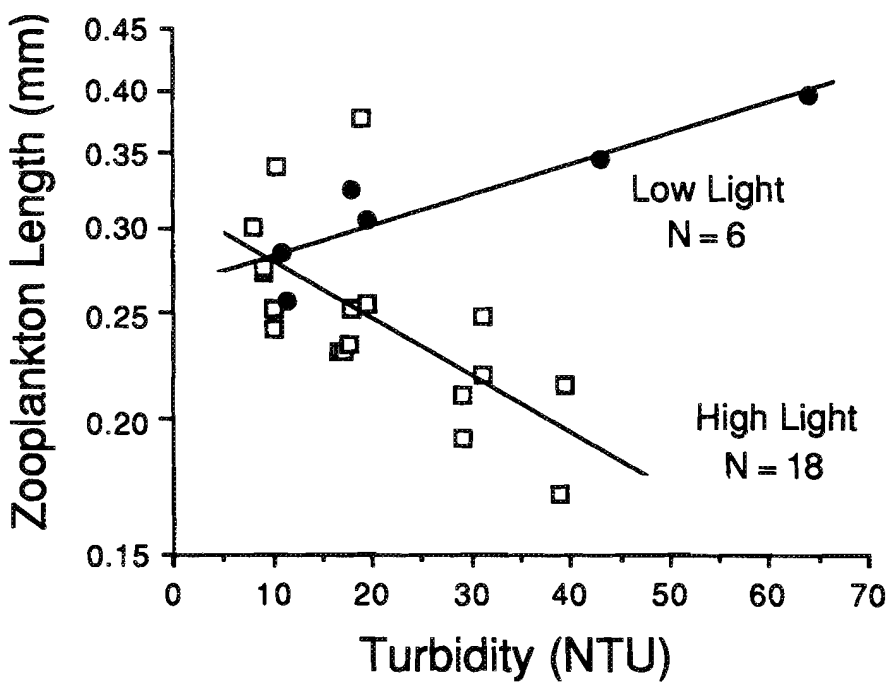

Fig. 4. Mean length of zooplankton in larval bluegill diets from enclosures along a turbidity gradient in Stonelick Lake, Ohio. See Table 1 for differences between light conditions. In high light, $r^{2}=$ 0.43 and $p=0.003$; in low light, $r^{2}=0.83$ and $p=0.012$.

plii $\left(r^{2}=0.43 ; p=0.003 ; N=18 ;\right.$ Fig. 4$)$. At 10 NTU, predicted mean prey length was $0.28 \mathrm{~mm}$ whereas mean length declined $30 \%$ to $0.19 \mathrm{~mm}$ at $40 \mathrm{NTU}$. When we compared prey length within a taxon, smaller cyclopoid copepods and copepod nauplii (i.e., composing 59 and $22 \%$ of prey in the diet across all turbidities) were consumed by larval bluegill as turbidity increased at high light $(F=3.61 ; \mathrm{df}=4,14 ; p=0.03$; MANOVA using Wilk's criterion, SAS Institute, Inc., 1985).

At low light intensity, bluegill consumed larger prey as turbidity increased $\left(r^{2}=0.83 ; p=0.012 ; N=6\right.$; Fig. 4). Mean prey length at low turbidity (11 NTU) was $0.28 \mathrm{~mm}$, the same as at high light. However, at high turbidity (43 and 64 NTU), larvae consumed prey that averaged $0.35 \mathrm{~mm}$ long, representing a $75 \%$ increase in mean prey length over that consumed in high-light sets at high turbidity. Also, at low light, size of cyclopoid copepods and copepod nauplii consumed increased from low to high turbidity $(F=9.17$; $f=4,4 ; p=0.02$; MANOVA). In summary, at high light, bluegill larvae tended to select smaller zooplankton with increasing turbidity whereas prey size increased when turbidity increased at low light.

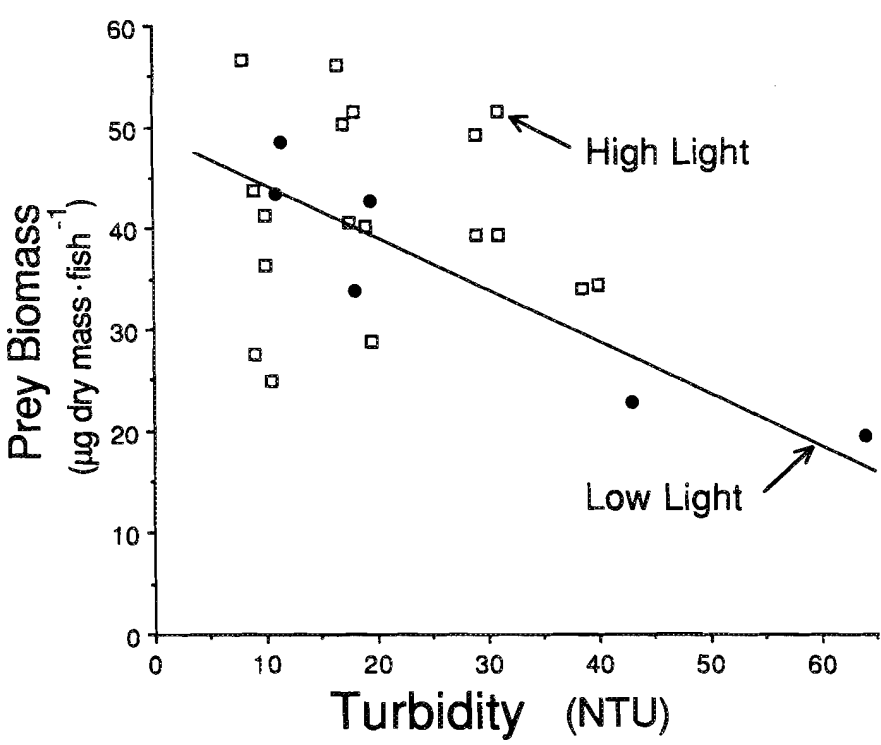

FIG. 5. Biomass of prey recovered from larval bluegill guts as a function of turbidity at high and low light in Stonelick Lake, Ohio.

\section{Biomass Consumed}

Because number of prey consumed increased and size of prey decreased with turbidity at high light, and because reciprocal results were obtained at low light, we compared dry mass of zooplankton consumed across turbidity. At high light, the increase in number of prey consumed was offset by a reduction in prey size, resulting in no significant relationship between turbidity and biomass consumed $\left(r^{2}=0.00 ; p=0.83, N=\right.$ 18; Fig. 5). However, at low light, biomass consumed declined with increasing turbidity $\left(r^{2}=0.85 ; p=0.009 ; N=6\right.$; Fig. 5). Therefore, whereas turbidity influenced selection of prey taxa consumed by larval bluegill, change in prey biomass consumed was detected only for the low-light condition.

\section{Discussion}

Foraging by larval bluegill was influenced by interaction between turbidity and light. When light intensity throughout enclosures exceeded $450 \mathrm{~lx}$, increasing turbidity caused larvae 
to select smaller prey both within and among taxa. However, biomass of prey consumed did not differ across turbidities because numbers of prey increased with turbidity. Conversely, when light intensity in large portions of enclosures fell below $3001 x$ during low ambient light conditions (i.e., set 3 ), both prey numbers and biomass consumed declined with increasing turbidity. These data provide insight into conflicting results in the literature for larval fish in which turbidity effects were measured at only one light intensity (i.e., either low or high light, Johnston and Wildish 1982; Boehlert and Morgan 1985; Breitburg 1988).

Johnston and Wildish (1982) found that larval Atlantic herring (Clupea harengus) consumed fewer prey as turbidity was increased from 0 to about 13 NTU at 300 lx (i.e., $20 \mathrm{mg}$ estuarine sediments $\cdot L^{-1}$ calculated from Breitburg 1988), while larval Pacific herring (Clupea pallasi) consumed more prey at $90 \mathrm{NTU}$ than in clear water when light intensity was $>800 \mathrm{~lx}$ (Boehlhert and Morgan 1985). Striped bass larvae also consumed fewer prey organisms from natural assemblages of copepods as turbidity increased at low light (i.e., $5 \mathrm{~lx}$; Breitburg 1988). Our field results support these observations, in which turbidity has negative effects on foraging only at low light, and may enhance prey contrast at higher light intensity, increasing prey detection and consumption by larvae (see Hinshaw 1985 for discussion of contrast).

Larval fish responses to turbidity have been explained in terms of reduced reaction distance with increasing turbidity, as occurs with juvenile and adult particle-feeding planktivores (Howick and O'Brien 1983; O'Brien 1987). However, relative to adults and juveniles, larval bluegill have poor visual acuity. Although bluegill larvae rapidly develop a complex visual system as they grow (Kawamura and Mukai 1984), reaction distance (i.e., acuity) is probably little more than one body length at a size of $12 \mathrm{~mm}$ total length (TL) (review for other species in Blaxter 1986; Wanzenbock and Schiemer 1989). In contrast, when bluegill are $31 \mathrm{~mm} \mathrm{TL}$, they possess retinas with a high density of rods and cones (Hairston et al. 1982; Breck and Gitter 1983), enabling them to detect zooplankton as far as $30 \mathrm{~cm}$ away (Vinyard and O'Brien 1976). When reaction distance is short, there are fewer suspended particles between predator and prey to reflect light and interfere with detection (i.e., much as fog affects long-distance vision, but has little effect on detection of close objects). Thus, while juvenile and adult bluegill exhibit an exponential decline in reaction distance with increasing turbidity (Vinyard and O'Brien 1976; Miner 1990), there may be little negative effect on reaction distance of larvae with sufficient light $(>300 \mathrm{~lx})$.

In contrast with the results at high light, increasing turbidity in the low-light set appears to have reduced light intensity below a threshold necessary for maximizing foraging rates by larval bluegill. Because larvae possess a rudimentary visual system with relatively few rods necessary for vision at low light intensity, feeding and growth can be negatively affected at low light (<100-300 1x, Blaxter 1986; Chesney 1989). In our experiments at low ambient light, high- and intermediate-turbidity enclosures contained extensive areas in which light intensity was $<3001 \mathrm{x}$ and prey consumption was depressed. However, in these in situ enclosures, why would foraging decline if larvae could use areas with optimal lighting (i.e., top $0.5 \mathrm{~m}$ )? These results suggest that larval bluegill were either using the lowlight regions of enclosures causing foraging success to decline or zooplankton were concentrating in the low-light refuge, thus having the same effect on bluegill foraging.
Actively foraging larval fish can undertake relatively extensive diel vertical migrations (e.g., 10-30 m, Fortier and Leggett 1983; Wurtsbaugh and Neverman 1988; Munk et al. 1989) and appear to select optimal light levels. Increasing turbidity also tends to cause larval fish to migrate up in the water column, potentially to locate optimal light conditions for foraging (Swenson and Matson 1976; Matthews 1984; Boehlert and Morgan 1985). Because zooplankton also exhibit both diel vertical migration and migrate toward the surface as turbidity increases (Swenson and Matson 1976; Zettler and Carter 1986), the potential dissociation between prey concentrations and optimal search habitat for larval fish has not been considered. In experimental tanks, freshwater cyclopoid copepods tend to aggregate near the bottom even at night (Soto and Hurlbert 1991). Our data suggest that high turbidity and low light may create a refuge for zooplankton prey. The recent literature on diel vertical migration of zooplankton as a behavioral response to both invertebrate and vertebrate predators supports this refuge hypothesis (Ohman 1990; Ringelberg 1991; Bollens and Frost 1991).

Similar vertical distributions of larval herring and zooplankton, however, suggest synchronous habitat use (Fortier and Leggett 1983), although these observations were made over $10-\mathrm{m}$ depth intervals. Because turbid conditions increase light attenuation rates, and thus compress light strata within shallow lakes (i.e., represented by our enclosures), zooplankton may concentrate within $50 \mathrm{~cm}$ of larval fish and still be within suboptimal habitat for fish foraging.

Zettler and Carter (1986) observed the progressive migration by zooplankters toward the surface along a turbidity gradient in a naturally turbid lake. In this deep lake (i.e., $50-60 \mathrm{~m}$ ), they were able to show that many zooplankton concentrated in the top 5-10 $\mathrm{m}$ at high turbidity (14.5 NTU). However, using light attenuation rates generated from our system at $10.5 \mathrm{NTU}$ in high light (see Table 1), light intensity at their high turbidity station was $<300 \mathrm{~lx}$ at a depth of about $2.5 \mathrm{~m}$. Thus, even with relatively fine-scale sampling (i.e., 5 -m depth intervals in a system $60 \mathrm{~m}$ deep), in turbid systems it is difficult to determine if zooplankton concentrate within optimal habitat for larval fish foraging.

In high-light conditions, consumption of smaller zooplankton with increasing turbidity may be explained using predictions from optimal foraging theory (Stephens and Krebs 1986). Increasing turbidity at high light may increase prey contrast causing larvae to detect and consume smaller, and potentially more profitable, prey. Large prey are not always the most profitable in terms of net energy gain and growth (Bence and Murdoch 1986; Confer and Lake 1987) owing to increased handling time, poor capture efficiency, reduced assimilation efficiency, or increased gut passage time, as has been shown for early juvenile yellow perch (Perca flavescens, 22-62 mm TL) (Mills et al. 1986; Confer and O'Bryan 1989; Confer et al. 1990). Selection by yellow perch for cyclopoid and calanoid copepods and small Daphnia increases as prey density increases in high light whereas selection for large Daphnia declines. In fact, yellow perch grow faster feeding on small copepods than on Daphnia (Confer and Lake 1987). However, energy ingested per unit time does not differ between yellow perch feeding on copepods or Daphnia, in spite of the fact that foraging costs should be higher for copepods given their greater escape ability (Drenner et al. 1978). Given this, the observed increase in selection for smaller prey items (i.e., for copepod nauplii and smaller prey within taxa), and the fact that biomass consumed 
did not change at high light, suggests that turbidity effects on larval fish are complex.

Results from this experiment point to strong interactions between turbidity and light intensity on larval fish foraging and help to explain conflicting results from previous laboratory studies. Rather than directly reducing foraging ability of larval fish by decreasing reaction distance, turbidity appears to affect larval foraging through a reduction in light intensity and possibly prey contrast. At low light, increasing turbidity causes a reduction in biomass of prey consumed by larval bluegill; however, even at these low-light conditions, optimal light intensity $(>450 \mathrm{~lx}$ ) occurred in the upper $0.5 \mathrm{~m}$ of each enclosure. Thus, the precise mechanism explaining reduced consumption of prey needs to be determined by quantifying larval bluegill and zooplankton vertical distribution and prey consumption along the vertical, low-light gradient. However, previous laboratory studies and our field experiment clearly demonstrate that explanations for larval fish responses to perturbations (e.g., increasing turbidity in coral reef communities, Roberts 1991) cannot be directly extrapolated from studies of juvenile and adult fish. Because of rapid ontogenetic changes, larval fish cannot be considered miniature adults.

When turbidity reduces light intensity to threshold levels $(<450 \mathrm{~lx}$ in our system), spatial overlap between predator and prey or prey-capture abilities appears to be reduced in shallow lakes, and larval bluegill growth may be inhibited. Because of highly size-dependent mortality from predation (Margulies 1990), even minor reductions in growth rate can have substantial effects on survival through this critical life stage.

\section{Acknowledgments}

We gratefully acknowledge the help of Penny Crane in all phases of this work and Robert Vice. Park Manager at Stonelick Lake. Wo thank E. Chesney, P.L. Chesson, K.R. Dabrowski, D.R. DeVries, G.G. Mittelbach, S.F. Srocznski, and T.E. Wissing for reading early drafts of this manuscript and T.G. Northcote and R.S. Gregory for constructive reviews. This research was supported in part by National Science Foundation grants BSR-8715730 and BSR-9107173 to R.A. Stein and Sigma Xi Grants-in-Aid-of-Research to J.G. Miner.

\section{References}

american Public Health association (aPHa), American Water Works Association, and Water Pollution Control Federation. 1985. Standard methods for the examination of water and wastewater. 16 th $\mathrm{ed}$. APHA, Washington, DC.

ARruda, J.A., G.R. MARZOLF, AND R.T. FALLK. 1983. The role of suspended sediments in the nutrition of zooplankton in turbid reservoirs. Ecology 64 : $1225-1235$

BarRetT, J.C., G.D. Grossman, AND J. Rosenfeid. 1992. Turbidity-induced changes in reactive distance of rainbow trout. Trans. Am. Fish. Soc. 121: $437-443$.

Bence, J.R., AND W.W. Murdoch. 1986. Prey size selection by the mosquito fish: relation to optimal diet theory. Ecology 67: 324-336.

BLAXTER, J.H.S. 1986. Development of sense organs and behavior of teleost larvae with special reference to feeding and predator avoidance. Trans. Am. Fish Soc. 115: 98-114.

BOEHLERT, G.H., AND J.B. MORGAN. 1985. Turbidity enhances feeding abilities of larval Pacific herring, Clupea harengus pallasi. Hydrobiologia 123: $161-170$.

Bollens, S.M., AND B.W. Frost. 1991. Diel vertical migration in zooplankton: rapid individual response to predators. J. Plankton Res. 13: 13591365 .

BRECK, J.E., AND M.J. GITTER. 1983. Effect of fish size on the reactive distance of bluegill (Lepomis macrochirus) sunfish. Can. J. Fish. Aquat. Sci. 40: $162-167$.

BRettBuRG, D.L. 1988. Effects of turbidity on prey consumption by striped bass larvate. Trans. Am. Fish. Soc. 117: 72--77.

BRLrTON. M.N. 1985. The effects of suspensoids on fish. Hydrohiologia 125: $22|-24|$.

CHESNEY, E.J. JR. 1989. Estimating the food requirements of striped bass larvac Morone saxarilis: effects of light, turbidity, and turbulence. Marr. Ecol. Prog. Ser. 53: 191-200.

Chesson. J. 1978. Measuring preference in selective predation. Ecology 59: $211-215$.

CHESSON. J. 1983. The estimation and analysis of preference and its relationship to foraging models. Ecology 64: 1297-1304.

COCHRAN. W.C. 1977. Sampling techniques. 3rded. John Wiley \& Sons. Inc.. New York. NY

CONFER. J.L.. AND G.J. LAKF. 1987. The influence of prey type on growth of young yellow perch (Perca flarescens). Can. J. Fish. Aquai. Sci. 46 1026-1032.

CONFER. J.L.. E.L. MILLS, AND L. O'Bryan. 1990. The influence of prey abundance on species and size selection by young yellow perch (Perca fluvescens). Can. J. Fish. Aquat. Sci. 47: 882-887.

CONFER. J.L.. AND L. O'BRYAN. 1989. Changes in prey rank and preference by young planktivores for short-term and long-term ingestion periods. Can. J. Fish. Aquat. Sci. 46: 1026-1032.

Crowl. T.A. 1989. Turbidity effects on largemouth bass - crayfish interactions: a predation component model. Hydrobiologia 183: 1.33-140.

DeVries, D.R.. R.A. Stein. I.G. Minf.r. and G.G. Mitteibach. 1991. Threadfin shad as supplementary forage: consequences for young-ot-year fishes. Trans. Am. Fish. Soc. 120: 368-381.

Drenner. R.W.. J.R. StRICKI.ER, AND W.J. O'BRIEN. 1978. Capture probability: the role of zooplanktore escape in selective feeding of planktivorous fish. J. Fish. Res. Buard Can. 35: 1370-1373.

Dumont, H.J., I. VAN DE. Vel.de, AND S. Dumont. 1975. The dry weight estimate of biomass in a selection of Cladocera. Copepoda. and Rotifera from the plankton. periphyton and benthos of continential waters. Oecologia (Berl.) 19: 75-97.

ForTIER. L.. AND W.C. LEGGETr. 1983. Vertical migration and transport of larval fish in a partially mixed estuary. Can. J. Fish. Aquat. Sci. 40:15431555.

Gol.DSBOROUGH. W.J. . AND W.M. KemP. 1988. Light responses of a submersed nacrophyte: implications for survival in turbid tidal waters. Ecology 69 1775-1786.

HAIRSTON, N.G. JR., K.T. Li, AND S.S. EASTIR. 1982. Fish vision and the detection of planktonic prey. Science (Wash. DC) 218: 1240-1242

HiNSHAW. J.M. 1985. Effects of illumination and prey contmast on survivat and growth of larval yellow perch Perca flavescens. Trans. Am. Fish. Soc. 114: 540-545.

HowICK, G.L., AND W.J. O'BRIEN. 1983. Piscivorous feeding behavior of largemouth bass: an experimental analysis. Trans. Am. Fish. Sox. 112: $508-516$.

JOHNSTON. D.D.. AND D.J. WILDISH. 1982. Effect of suspended sediment on feeding by larval herring (Clupea harengus harengus L.) Bull. Environ. Contan. Toxicol. 29: 261-267.

Kawamura, G., and Y. Mukal. 1984. Behaviour and development of sense organs during early stages of bluegill. Mini-rev. Data File: Fish. Res. 3: $49-54$.

LAURENCE, G.C. 1971. Digestion rate of larval largemouth bass. N.Y. Fish Game J. 18: 52-56.

MARGUL.JES, D. 1990. Vuinerability of larval white perch. Morone americana. to fish predation. Environ. Biol. Fishes 27: 187-200.

MATTHEWS. W.J. 1984. Influence of turbidity inflows on vertical distribution of larval shad and freshwater drum. Trans. Am. Fish. Soc. 113: 192-198.

Mill.er, T.J., L.B. Crowder, J.A. Rice, And E.A. Marschall. 1988. Larval size and recruitment mechanisms in fishes toward a conceptual framework. Can. J. Fish. Aquat. Sci. 45: 1657-1670.

Mills, E.L., J.L. CONFER, AND D.W. KRETChMER. 1986. Zooplankton selection by young yellow perch: the influence of light, prey density, and predator size. Trans. Am. Fish. Soc. 115: 716-725.

MiNER, J.G. 1990. Turbidity-mediated predator-prey interactions among piscivores, prey fishes, and zooplankton. Ph.D. thesis, The Ohio State University, Columbus, $\mathrm{OH}$.

Muncy, R.J., J.J. Atchison, R.V. Bul.kley, B.W. Menzel. L.G. Perry, AND R.C. SUMMERFELT. 1979. Effects of suspended solids and sediment on reproduction and early life history of warmwater fishes: a review. U.S. Environmental Protection Agency. Corvallis, OR.

Munk, P., T. KIORBOE, AND V. Cisistinsen. 1989. Vertical migrations of herring, Clupea harengus, larvae in relation to light and prey distribution. Environ. Biol. Fishes 26: 87-96.

O'BRJEN, W.J. 1987. Planktivory by freshwater fish: thrust and parry in the pelagic. In W.C. Kerfoot and A. Sih [ed.] Predation: direct and indirect 
impacts on aquatic communities. University Press of New England, Hanover, NH.

OHMAN, M.D. 1990. The demographic benefits of diel vertical migration by zooplankton. Ecol. Monogr. 60: 257-281.

RINGELBERG, J. 1991. Enhancement of the phototactic reaction in Daphnia hyalina by a chemical mediated by juvenile perch (Perca fluviatilis). J. Plankton Res. 13: 17-25.

ROBERTS, C.M. 1991. Larval mortality and the composition of coral reef communities. Trends Ecol. Evol. 6: 83-86.

SAS INSTITUTE, INC. 1985. SAS user's guide: statistics version 5 edition. SAS Institute, Inc., Cary, NC.

Soto, D., AND S.H. HurLbert. 1991. Long-term experiments on calanoidcyclopoid interactions. Ecol. Monogr. 61: 245-265.

StEPHENS, D.W., AND J.R. KREBS. 1986. Foraging theory. Princeton University Press, Princeton, NJ.

SWENSON, W.A., AND M.L. MATSON. 1976. Influence of turbidity on survival, growth, and distribution of larval lake herring (Coregonus artedii). Trans.
Am. Fish. Soc. 105: 541-545

VINYARD, G.L., AND W.J. O'BRIEN. 1976. Effects of light and turbidity on the reactive distance of bluegill (Lepomis macrochirus). J. Fish. Res. Board Can. 33: 2845-2849.

WanZenBoCK, J., AND F. SCHEMER. 1989. Prey detection in cyprinids during early development. Can. J. Fish. Aquat. Sci. 46: 995-1001.

Werner, E.E., AND D.J. HALl. 1988. Ontogenetic habitat shifts in bluegill: the foraging rate - predation risk trade-off. Ecology 69: 1352-1366.

WERNER, R.G. 1967. Intralacustrine movements of bluegill fry in Crane Lake, Indiana. Trans. Am. Fish. Soc. 96: 416-420.

WILBER, C.G. 1982. Turbidity in the aquatic environment. C.C. Thomas Publishing, Springfield, IL.

Wurtsbaugh, W.A., AND D. Neverman. 1988. Post-feeding thermotaxis and daily vertical migration in a larval fish. Nature (Lond.) 333: 846-848.

Zettler, C.D., AND J.C.H. CARTER. 1986. Zooplankton community and species responses to a natural turbidity gradient in Lake Temiskamig, Ontario-Quebec. Can. J. Fish. Aquat. Sci. 43: 665-673. 